\title{
Core Competencies for the Information Professions and the Evolution of Skill Sets ${ }^{1}$
}

\author{
by Stuart A. Sutton
}

In this article, we consider the mechanisms necessary to distill new skill sets from the profession's core competencies along three out of four dimensions that define practice for information professionals in general and librarians in particular. We explore the emerging information universe and the environmental factors shaping it in order to cast light on the emerging professional conflicts over appropriate niches in the new universe of information work. Abbott's processes of reduction and abstraction as mechanism for the expansion of redefinition of a profession's domain are examined along three practice dimensions: (1) the tool making dimension, (2) the information management (tool use) dimension, and (3) the agency (service) dimension.

\section{Introduction}

As the close of the 20th Century approaches, the profession of librarianship will be confronted with some of the greatest challenges it has ever faced. Not only will it be challenged to adapt to a dramatically changing information universe, but it will be challenged by others outside the profession who see the work that has traditionally been viewed solely within the domain of librarianshipas part of their own. It is far from clear that the profession of librarianship can confront either of these challenges successfully.

To address both of these inextricably related challenges, this paper will be divided into three parts. First, the emerging information universe will be discussed in order to frame the context of the domain of future professional practice as well as its core competencies. Second, the difficult question of how librarians might transform themselves in order to participate actively in that universe will be explored. And finally, some broad outlines of appropriate skill sets necessary to that transformation will be drawn along three (out of four) dimensions that define professional practice in this field.
Before it is possible to address the question of what core competencies will be needed in the 1990s and beyond, it is necessary to reach some level of agreement on what is meant when we speak of the core competencies of a profession. However, that question is inextricably bound to another-what is it that defines a profession? It is probably most useful in quickly answering both questions to assume a rather simplistic view of both the nature of professions and their defining core competencies. As a lawyer and as an information professional and as a librarian, it appears to this author that professions are basically defined by the societal problem (or set of problems) those professions choose to address.

Given a finite societal problem capable of solution through service, the profession develops the tools, methodologies and service necessary to accomplish that task. For example, the lawyer's profession deals with the social problems of conflict avoidance and resolution. Over the centuries, lawyers (along with the judicial system) have developed procedural rules and methodologies for interpreting and applying law in service of its defining social problem.

Of course (and this will become important laterin the discussion),

\footnotetext{
1 This paper is an adaptation of a talk delivered at the Special Libraries Association 85th Annual Conference, Atlanta. June 1994. Much of the content is the result of numerous conversations with Nancy Van House, Acting Dean. School of Library and Information Studies at the University of California at Berkeley. However, responsibility for the half-baked nature of some of the ideas rests with this author and not with Acting Dean Van House. A more thorough explanation of our thinking is forthcoming.
} 
the lawyer's profession is only one of a number of professions that have carved out their own niches from the context of the same societal problem-witness family and marriage counseling and therapists of all sorts to say nothing of arbitrators. Thus, we must conclude that while the societal problem defines a domain of practice that may be shared by more than one profession, each approaches resolution of the problem within the context of a set of core competencies or functions that are more or less its own.

Given this definition of a profession, the core competencies of librarianship are those rather immutable and abstractly stated competencies which are central to its ability to solve the societal problem it has elected to address. We keep the definition of the societal problem the profession librarianship has chosen to address quite simple by framing it merely as the "information problem"-the need for a mediated synapse between an individual information need and one or more information stores containing potentially fulfilling answers.

As an anchor to what remains to be said, we need to bear in mind as we look at the shift in what the information universe is going to be like that the core competencies of the profession will remain much the same. Ross Atkinson (1993, p.201) recently reassessed the defining competencies in stating that the aspects of practice that librarians do best are the "[s]electing, distinguishing, referring to, and otherwise privileging of individual information units." We do not think that these core competencies are going to change as the society moves deeper into the informaticn age and begins to traverse that mythical information superhighway.

As Atkinson points out, these functions have been handled traditionally through processes such as collection development, cataloging, and reference. In the future, the professional will perform the same functions but will do them in markedly different ways. There will be different tools and different services models to accommodate those funcions in a changing context; however, the core competencies will remain much the same. That is why we call them "core"-there is something slightly inmutable about what it is that the profession docs best.

Given that statement, it should become increasingly obvious that the profession should not be looking at the core competencies as much as at the processes by which new skill sets are derived from them to address new contexts in which those competencies will be played out. Notice that the inquiry should be focused on the process by which new skill sets are derived and not on the skill sets themselves. These is a real and present danger here in gelling too caught up in particular skills. "Skills obsession" is perhaps appropriate in periods of professional stability, in periods when change is stable and paced slowly. But skills obsession in a period of swift environmental change can be catatstrophic.

It is useful in helping beginning students in this field to understand the dangers of skills obsession by exploring their expectations of professional study. It is our impression that on the way to school on the first day, most students stop off at Scars and go to the tool department where they purchase a little red metal tool kit of the kind mechanics and carpenters use. They bring it to school with them the first day, they set it down and say"fill it"give me Dewey, give me LCSH, give me some skills in how to search Dialog. Any many fill up the tool kit and march away at the end of their formal education believing they are pepared for the remainder of their professional lives.

There may have been a time when change in this profession was so slow that such a mind set would work, when one could sail through ones professional life with the tattered tool kit still intact and equally tattered skills still relevant. If there were ever such a time in this profession, it is gone forever.

The "little red tool kit" sort of skills acquisition is not the answer to the challenges to come. Instead, we need to look at how we might educate information professionals capable of continuously deriving the new skills from the core competencies which will be necessary to meet the challenges of a shifting domain of professional practice.

There are two ways of looking at how we might derive those skills sets. One way is to look at the demands of the existing professioni.e., to look at the pressures on the profession's current tools and service models to determine what kinds of skill sets are necessary tohandle today's practice, For example, many librarians remember catalogs when they were still made of cards. Suddenly, along came the computer and new skill sets were required to deal with transaction processing facilitated by the machine. And many librarians acquired those skills. But what they were actually doing was much the same, just made easier and somewhat more efficient by the computer. In other words, these new skills made it possible to do the same thing better.

A second way to look at deriving new skills-and the one used here for the remainder of the discussion-is to absolutely assume a change of context: to assume that we are in a period of extremely rapid change and that what we really need to be looking at is what is it that we might be doing that is new and better. What is i that we could be doing that will take us beyond the current constraints of our own profession? While this discussion will touch on the first of these two ways of viewing the task at hand, it will dwell on the second.

\section{The Emerging Information Universe-Environmental Fac- tors}

In order to understand the necessary development of new skill sets, we must first look at the information universe that is evolving. Second, we have to detennine how librarians are to continually realign themselves and what they do as professionals in that evolving context.

For the most, the environmental factors that are shaping where the information universe is going are quite familiar and only the briefest statements of those factors need be chronicled here. Among those factors are the following: 
The fusion of computing and relecommunications: Moore's Law which states that computing power will double every eighteen months is holding true in all importantrespects. Communications technologiessuch as the evolving Asynchronous Transfer Mode (ATM) and the broadband networks are exciting the interest of the telephone, cable and utility companies nation wide. One cannot pick up the newspaper without finding something about "information" and these companies. When these two rapidly developing technologies are wed, what emerges is a totally new environment for information storage, distribution, manipulation and use.

The fusion of media: 2 'The digital revolution is giving rise to new acceptable forms of literacy born in multiand hypermedia that are going to change funamentally our definition of literacy as it takes us well beyond the linear constraints of text. Many see this revolution already taking hold in their children and grandchildren. Multi- and hypermedia are spawning whole industries in California's Silicon Valley and San Francisco's Multimedia Gulch.

Information abundance and complexity: As anyone who has been out on the Internet can attest, when the first two factors are combined, the result is an abundance of information, ${ }^{3}$ a complexity of information structures that has never before been experienced, and client/server computing models that incorporate the networking of geographically dispersed products of the intellect - from human expertise to the human record.

Social Computing: And now, in the 90), we are experiencing the rapid emergence of what John Seely Brown from Xerox PARC calls social (as opposed to personal) computing.

\section{Competition in the Information Universe}

These factors are defining rapidly a whole new environment for information storage, retrieval and management. And, in a logically parallel development, these same factors are defining a new domain of practice for librarianship - a new domain in which other professions and other disciplines are also interested and will compete with librarianship for the same (or overlapping) niches.

Many practitioners are already beginning to sense the competition that is out there. Information, as the coinage of the information age, will define economic power with increasing frequency and create what a recent issue of Fortune magazine calls the illperceived "new economy" that will reshape this country and the world. The lawyers and the economists am?ng us know that power attracts players. So, librarianship as a profession is not alone in this new domain. In fact it has very, very powerful company that can be seen in the mad scramble of information content and information transport providers to merge and otherwise realign.

In all this activity to carve out niches and to realign domains, librarians should hear this clarion call: libraries and librarians do not have very high visibility in this emerging domain. As professionals, librarians are going to have to work actively to stake a claim in this new domain since it is far from obvious to the rest of the world that they have a significant role to play.

To illustrate the accuracy of that statement, we like to tell the story of a statement allegedly made by Chancellor Munitz of the Cálifornia State University system. Chancellor Munitz presides over the largest complex of higher education in the world which is getting ready to build the state-of-the-art campus for the 21 st century at Fort Ord on Monterey Bay. According to a reporter for the San Francisco Chronicle, the Chancellor says that there will be no library on the new campus. ${ }^{4}$ Now, recalling Richard Ross' talk at the opening Plenary Session for this Annual Meeting concerning the natural rubber-band-like tension between organizational vision and reality, some would say that the Chancellor's vision is an appropriate one, while others might say that the hook on the end of the rubber band which should be attached to reality is missing.

Whatever side one lands on, what is interesting here about the newspaper report is the fact the Chancellor Munitz allegedly named the following sorts of partners in building the digital library that will exist at Monterey Bay - PacBell, Apple and IBM. Supposedly, there was not a single mention of librarians or the skills, tools or service models that have been developed over the last century: not a word. We think that should give us pause. It should also make us wonder how are we, as a profession, going to convince the Chancellor Munitzs of this world that we belong in the emerging information universe? In other words, how are we to assert professional dominion over a niche in this emerging environment?

Andrew Abbot (1988) provides us with a mechanism for examining the phenomenon of shifting and expanding professional domains in his explication of the ecology of professions. ${ }^{5} \mathrm{We}$ will review those mechanisms briefly and then apply them to the context of librarianship.

\footnotetext{
2 Michael Buckland notes that the use of the term "fusion" in this context might not be accurate. In the context of digital storage, we are really addressing monomedia; however, even in that context, music remains music and images remain images and are, therefore, not "fused."

3 Note that we did not say necessarily "good" information.

${ }^{4}$ In all fairness to Chancellor Munitz, this anecdote is based entirely on a single newspaper article. Having been frequently misquoted and having the context of our words distorted in the popular press, we think there is probably a more than $50 / 50$ chance that the report is totally inaccurate. Nevertheless, it illustrates a point we believe to be generally true.

${ }^{5}$ We use Abbott's analytic framework without adopting his analysis of the information prof essions.
} 
According to Abbot, when a profession wants to shift or expand its domain, there are two ways to argue the validity of such a shift or expansion - reduction and abstraction. Reduction shows that the solution to some problems in the new domain (e.g.,cyberspace or how one wishes to define that domain) is reducible to a solution which already exists in the profession's current jurisdiction. A reductionist argument might be that $\mathrm{LCSH}$ is as useful a tool for accessing information in cyberspace as it is in a traditional library. Basically a ludicrous idea since many believe that LCSH ill-serves our patrons even in the context of the modern OPAC let alone in cyberspace. We conclude that reductionist arguments will not work since few of the tools designed to serve the practice of librarianship as it exists have a direct application in that environment.

Abstraction is the second, and much more powerful, argument. Abstraction is a process by which the profession argues (and ultimately demonstrates) that the abstract knowledge which underlies the tools and service models in the profession's current domain are applicable in the new one. A simple example of abstraction might be the argument that classification theory underlies many of the tools we have developed, and those theories have application to the development of new tools suitable to the new domain.

Thus, according to Abbott, professions use these two mechanisms (reduction and abstraction) to argue for an appropriate niche and to develop new tools and service models which justify a move into new territory. Using Abbott's basic conclusions, these two mechanisms are the weapons needed in this profession's competition with the Pacl3clls, the Apples, and others. However, there is a problem, and we believe the problem is this: we can abstract all we want from our current set of tools and service models and we can do reduction all we want and we still will not win. We still cannot make that transition because of a third mechanism Abbott does not identify - new knowledge.

If one looks at the faculties of the schools of library and information science in the United States that are moving forward successfully in preparing themselves to educate professionals tor the emerging domain, they are developing interdisciplinary laculties. They are incorporating people with backgrounds in cognitive science, communications, and a host of other disciplines and fields of concern to the "information problem." They are actively trying to wed new knowledge with the profession's extant knowledgebase in order to hybridize a new professional who can function in the emerging domain. If the schools of library and information science do their jobs well, it will be to educate professionals who can do the kind of abstracting necessary to create the new tools and service models for a new environment that is just around the comer. If we are are not able to do that, the profession of librarianship is in deep, deep trouble.

\section{Dimensions of Practice}

The deriving of new skill sets from the core competencies for an expanding or shifting professional domain through the processes of reduction, abstraction and new knowledge acquisition will take place (if at all) along four dimensions of professional practice:

The tool making dimension,
The information management (or tool use)
dimension,
The agency dimension (we like to call it serv-
ice), and
The management of information organizations
dimension.

The ordering here is significant. Perhaps, while not necessarily denoting their importance in daily practice, we believe the order reflects the survival order for the profession; i.e., the order of mastery for survival of the profession as it transitions to the new environment.

\section{Tool Making Dimension}

The tool making dimension tends to confuse people; they do not understand what is meant when we speak of librarians as tool makers. As a profession, we use tools and servicemodels to solve the problems that the profession has chosen to address. For example, LCSH is a tool; the Dewey Decimal system is a tool. ${ }^{6}$ Dewey was a librarian but he was also a tool maker. Practitioners at the Library of Congress and in Europe were librarians and tool makers when they laid the conceptual foundations for LCSH and other organizational schemes.

In this profession and in the schools of library and information science, we have largely abdicated our role as tool makers. There was a great period of tool making in librarianship - librarianship's "golden age of tool making," if you will - in the late 19th and early 20ut centuries. Then, afer the First World War, something happened. The profession went on auto-pilot; it went to sleep and its practitioners became mere tool users. Tool making was someone else's problem - now it's the vendor's problem. As a result, we lost much of the power to enable the profession. ${ }^{7}$

An exanple might help. In general, librarians thathave ventured out onto the Internet with Archie, Veronica, WAIS, World Wide Wcb and other access tools - and please note, tools created by someone else - have viewed their role in the following sorts of terms:

\footnotetext{
6 The phrase "tool maker" includes not only actual tools such as LCSII but also the service models developed to address the societal problem.

7 In general, special librarians may represent the only exception to this abdication. Unlike the public and acadenic libraries, the richly varied contexts of speciallibrarypractice frequently required developing new designs, technologies and techniques in order to satisfy needs for nontraditional organizational schemes and service models. This stands in sharp contrast to the near rote application of existing tols such as LCSH, Dewey, and LCC in the public and acadenic libraries. Unfortunately, these issues in special librarianship play a small role in library and information science education.
} 
As complainers about the primitive nature of these tools and how they will not scale up to the challenges of networked global information; and

As innocent (and perhaps victimized) users, eagerly waiting for someone else (perhaps PacBell, perhaps Apple, perhaps IBM?) to develop acceptable information retrieval tools.

The survival of the profession (to say nothing of playing a significant role in the emerging information universe) will require finding adaptive solutions for the new contexts and the profession must begin to do so with a perhaps not so simple reawakening - a Renaissance of its role as tool makers in this new domain. To do so, its practitioners will have to go back to Abbott's "abstraction" to distill the existing professional knowledge-base. Then, that knowledge-base must be wed to new knowledge from outside the profession (c.g., human factors, educational psychology, computer science, cognitive science) in order to create new tools and new service models for new contexts. While this re-awakening will require developing highly technical backgrounds in many instances, it is a development that must be pursued if the tool making function is to be reassumed thus enabling the profession to move into new niches and to expand the old.

\section{Information Management Dimensions}

To address the second dimension, the information management (tool use) dimension and to see where professionals might develop new skill sets that will take them into cyberspace, we need to return to Atkinson's remark (1993, p. 201) that the profession is about the "[s]electing, distinguishing, referring to, and otherwise privileging individual information units." We observed earlier that one of the old mechanisms for performing these functions was the process of collection development. We will explore the information management dimension using that core competency.

Now, we all know what collection development is, or, at least we think we know what it is. But how do we abstract its foundation in order to carry it into cyberspace? To suggest an answer, let us engage in some rumor mongering. There was a rumor some time ago that Harvard Law had no collection policy - word had it that if it existed, Harvard would buy it. While most likely a myth, it is nevertheless a very instructive one in that it suggests a collection development continuum. This mythical Harvard Law can be placed at one end of that continuum and at the other end there is the library that functions under severe economic constraints. As one moves along that continuum from the mythical Harvard Law to the library operating under severe economic constraints, we suggest that the collection development librarian engages in a process of building an opinion piece. In other words, at points on the continuum far distant from Harvard Law, the library becomes an expression of the librarians's opinion - the librarian's opinion of the best that is out there and how to get it.
Now, we think the "library as opinion piece" is a good thing. In fact, we believe that it is this professional ability to express such an opinion that will define collection development in this new information universe unfolding before us. The question needing to be asked is how do we carry the structuring of opinion pieces over into a universe where we do not necessarily collect information containers as we have in the past? How do we do collection development in cyberspace?

As librarians, we will build opinion pieces of networked information by what we point to. For example, librarians out in front putting up Mosaic clients, servers and home pages are not only authoring in a new environment, they are doing collection development and they are developing a new form of bibliography. And, they are doing both in a new way using new tools. They are engaging in a very healthy form of adaptive behavior rooted in the profession's core competencies: deciding what is useful in all of the garbage that will flood the networks and pointing to it building what one might call information architectures. Thus, collection development will become more like authoring and publishing with librarians structuring information architectures of resources located on the global Internet and on the library's own servers. In aggregate, the result will be overlapping webs of opinion - webs of opinion very much akin to the traditional library while nevertheless standing in sharp contrast. Thus, even collection development has a direct corollary in the emerging environment.

The possibility of our potential professional role in this dimension of practice was recently driven home by Paul Saffo (1994, p.74) of the Institute for the Future when he said of the information superhighway in Wired magazine in an article titled "It's the Context, Stupid".:

It is this plethora of content that will make context the scarce resource. Consumers will pay serious money for anything that helps them sift and sort and gather the morsels that satisfy their fickle media hungers. The future belongs neither to the conduit or content players, but those who control the filtering, searching, and sense-making tools we will rely on to navigate through the expanses of cyberspace.

According to Saffo, the future will belong neither to the Baby Bells and/or the cable companies nor to the Time Warners, the Mead Datas, nor the myriad resources on the Internet. Rather it will belong to the creators of context of the sort we have been alluding to in our comments. While in his article Saffo is speaking of Knowbots and other computerized tools, librarians could, should and will play the context providing role described by Saffo. 


\section{Agency or Service Dimension}

The last of these dimensions of practice to be addressed here is the agency dimension or the service or reference context. ${ }^{8}$ While the agency dimension is critically important, we are not going to say much about it in this discussion because we think the readers of this journal, as special librarians, are on the forefront of development of this dimension and are already defining the new skills that will shape professional practice in the new information environment.

Special librarians were the first in the profession to define an alternative to the traditional resource provision model of service in the form of consultative models rooted more directly in solving the information need of the patron. Special librarians were among the first to recognize the inadequacy of a service model in which the patron's need for a specific answer is addressed by providing a number of resources potentially containing that answer. A model in which the last mile to extracting an answer has to be walked by the patron simply does not meet the needs of users in the context of most special libraries. For example, most attorneys would not be satisfied with a stack of resources provided by the law firm librarian that contained the possible answer when he or she wanted the actual answer.

The attributes that define a service model that will satisfy a user such as the lawyer just described are ones we have heard before: (1) the right information, (2) to the right person, (3) at the right time. To these attributes, the skills necessary to deliver on the modelare relatively obvious. Unfortunately, in many/most/all of the schools of library and information science, instruction is stuck on the resource provision model.

\section{Conclusion}

In conclusion, we would like to suggest a sort of mind game in which the schools of library and information science and the profession reverse one fundamental assumption underlying our mental model of professional education in this ficld. That assumption is this: in the library schools in the 70s and early $80 \mathrm{~s}$ it was taken for granted that the professionil would manage or work in a library environment which would collect containers of information, organize them and make them accessible. That environment would be finite, it would fit within certain walls. However, during that same period we were confronted with matters such as Dialog that did not fit the mental model or its underlying assumption. And so, as an uncomfortable appendage, we cloned instruction in networked information.
We would like to suggest that it might be useful to reverse the mental model and look at educating students that must structure and navigate geographically dispersed digital information and who might manage (incidentally and possibly quite tangentially) some small number of non-digital information bearing objects. If we reverse this underlying assumption of education and practice we will come up with the skills sets necessary to the new contexts without needing to ask the so-called experts.

Mind games aside, we must educate students through a transition period to an ill-defined emerging information universe who are as comf ortable with SGML and HTML tagging and structuring networked information resource architectures for Mosaic and other evolving tools as building catalogs with AACR2 and the MARC formats. We have to educate students who are as comfortable with information synthesis and the production of tailored information products for specif ic users and user groups as with the simple provision of resources. And we must again assume a strong tool making role as we vie for new territory and the redefinition of the profession.

\section{REFERENCES}

Abbott, Andrew Delano. (1988) The System of Professions: An Essay on the Division of Expert Labor. Chicago: University of Clicago Press.

Atkinson, Ross. (1993) "Networks, Hypertext, and Academic Information Services: Some Long-Range Implications." College \& Research Libraries 54(3): 199-215.

Saffo, Paul. (1994) “It's the Context, Stupid." Wired 2(03): 745.

Stuart A. Sutton is Associate Professor and Director of the San Jose State University School of Library and Information Science. $\mathrm{He}$ is a member of the California Bar with a specialization in intellectual property.

\footnotetext{
8 We onit the management of information organization dimension for one reason: we think it the least important when it comes to the survival or expansion of the current professional domain. We recognize that others night lake serious issue with this statement.
} 